\title{
Jornalismo científico na América Latina: registro histórico do Primeiro Seminário Interamericano realizado na região em 1962
}

Science journalism in Latin America: historical record of the First Interamerican Seminar held in the region in 1962

Periodismo científico en América Latina: registro histórico del Primer Seminario Interamericano realizado en la región en 1962

DOI: https://doi.org/10.1590/1809-58442021113

\section{Luisa Massarani ${ }^{1}$}

http://orcid.org/0000-0002-5710-7242

${ }^{1}$ (Fundação Oswaldo Cruz, Casa de Oswaldo Cruz, Instituto Nacional de Comunicação Pública da Ciência e Tecnologia. Rio de Janeiro - RJ, Brasil).

\section{Resumo}

Neste artigo, temos o objetivo de resgatar a memória do Primeiro Seminário Interamericano de Jornalismo Científico realizado na América Latina, em 1962, no Chile. O seminário foi o ponto de partida para uma série de eventos sobre o tema em outros países latino-americanos, em um movimento que culminou na criação da Associação Ibero-americana de Jornalismo Científico e de associações nacionais na região. Analisaremos, em particular, os personagens e as principais discussões presentes no evento, neste artigo destinado a seção Arena, na qual se inserem textos de reflexão com mais liberdade formal.

Palavras-chave: Jornalismo científico. divulgação científica. popularização científica. História. José Reis. América Latina.

\begin{abstract}
In this article, we have the objective of retrieving the memory of the First Interamerican Seminar on Science Journalism held in Latin America, in Chile, in 1962. The seminar was the starting point for other events on the field in other Latin American countries, in a movement that culminated in the creation of the Ibero-American Association of Science Journalism and of national associations in the region. We will analyse in particular the characters and main discussions present at the event in this article target to the section Arena, which includes reflection texts with more formal freedom. Keywords: Science journalism. science communication. science popularisation. history. José Reis. Latin America.
\end{abstract}




\section{Resumen}

En este artículo, tenemos el objetivo de rescatar la memoria del Primer Seminario Interamericano de Periodismo Científico realizado en América Latina, en 1962, en Chile. El seminario fue el punto de partida para una serie de eventos sobre el tema en la región otros países latinoamericanos, en un movimiento que culminó en la creación de la Asociación Iberoamericana de Periodismo Científico y de asociaciones nacionales en la región. Analizaremos en particular los personajes y las principales discusiones presentes en el evento, en este artigo destinado a la sección Arena, en la que se insertan textos de reflexión con más libertad formal.

Palabras-clave: Periodismo científico. divulgación de la ciencia. popularización de la ciencia. Historia. José Reis. América Latina.

\section{Introdução}

Em um encontro sobre jornalismo científico, um dos organizadores fala, em seu discurso de abertura, que a ciência nos países latino-americanos é pouco conhecida pela sociedade e pelos tomadores de decisão, o que faz com que haja uma situação de cortes na pesquisa científica e evasão de cérebros.

A cena poderia ter acontecido nos dias de hoje. Mas ocorreu em 1962, no que foi, até onde sabemos, o Primeiro Seminário Interamericano de Jornalismo Científico realizado na América Latina. O evento, embora pouco conhecido na atualidade, na época chamou a atenção da mídia, inclusive rendendo duas capas na Folha de S.Paulo ${ }^{1}$.

Já tínhamos lido referências a este evento, por exemplo, em relatos do jornalista espanhol Manuel Calvo Hernando (2005, 2006), personagem que teve uma contribuição fundamental no movimento que levou ao jornalismo científico latino-americano, do qual participaram vários entusiastas, entre eles, Antonio Cacua Prada (Colômbia), Arístides Bastidas (Venezuela), Jacobo Brailovsky (Argentina), José Reis (Brasil) e Sergio Prenafeta (Chile). No entanto, apenas com a chegada do acervo de José Reis - considerado ícone da divulgação científica no Brasil - à Casa de Oswaldo Cruz (ver próximo item neste artigo) tivemos acesso a documentos que deram mais informações para entender melhor as discussões ocorridas no evento, que foi um marco importante na consolidação do jornalismo científico no Brasil e em outros países da América Latina, fruto de um movimento organizado, que envolveu diferentes atores sociais.

Neste contexto, o evento de 1962 foi o ponto de partida para outros eventos sobre o tema, entre eles: em 1965, no Equador, em 1966, na Argentina, na Colômbia, em 1969, em Madrid (CALVO HERNANDO, 2005, 2006, MASSARANI, 2010, MASSARANI et al., 2012). No evento de Madrid foi criada a Associação Ibero-americana de Jornalismo Científico. Com a associação, iniciou-se uma série de congressos ibero-americanos: Venezuela (1974),

1 “A AL debate 13 out 1962 debate jornalismo científico, com base em trabalho brasileiro”, Folha de S.Paulo, 13/10/1962, e "I Seminário de Jornalismo Científico”, Folha de S.Paulo, 18/10/1962. 
Espanha (1977), México (1979), Brasil (1982), Espanha (1990), Chile (1996) e Argentina (2000) (CALVO HERNANDO, 2005, 2006).

A associação ibero-americana também estimulou a criação de associações nacionais, criadas como parte desse movimento latino-americano: Argentina (1969), Venezuela (1971), Chile (1976), Colômbia (1976) e Brasil (1977). Como expressão de valorização do campo, o governo brasileiro criou, em 1978 - portanto, no ano seguinte da criação da Associação Brasileira de Jornalismo Científico -, o Prêmio de Divulgação Científico José Reis, em homenagem a esse personagem, ícone da divulgação científica brasileira e que fez parte do movimento do jornalismo científico no Brasil e na América Latina. O entusiasmo pelo jornalismo científico se manteve forte em vários desses países nas décadas seguintes. Mais recentemente, no entanto, Associação Ibero-americana e pelo menos duas dessas associações - a da Argentina e do Brasil - perderam fôlego, sendo essas duas últimas substituídas por redes que congregam gerações mais jovens, a saber, a Rede Argentina de Jornalismo Científico, criada em 2007, e a RedeComCiência - Rede Brasileira de Jornalistas e Comunicadores de Ciência, em $2018^{2}$.

\section{José Reis e seu acervo}

Como mencionado anteriormente, José Reis teve um papel fundamental na consolidação do jornalismo científico no Brasil e na América Latina.

É justamente por meio de José Reis e seu acervo que surgiu a ideia deste artigo, cujo objetivo é analisar o seminário ocorrido em 1962, em particular os personagens e as principais discussões presentes no evento.

Médico, virologista, patologista pelo Instituto Oswaldo Cruz, jornalista e escritor, José Reis desenvolveu importante papel na construção da ciência brasileira e na divulgação científica ((MASSARANI; BURLAMAQUI; PASSOS, 2018). Trabalhou no Instituto Biológico, em São Paulo, e se destacou pela fundação e consolidação da Sociedade Brasileira para o Progresso da Ciência (SBPC), em 1948. Um ano depois ajudou a criar a revista Ciência e Cultura, da SBPC, tornando-se seu editor. A trajetória do cientista é marcada pela diversificação. Publicou livros infanto-juvenis, para adultos, novelas de rádios e artigos de Divulgação Científica para a Folha da Manhã (grupo Folha), na década de 1940. Na Folha de S.Paulo, na qual manteve uma coluna por seis décadas, foi diretor de redação de 1962 a 1968 e estimulou a criação do suplemento infantil do jornal, veiculando temas de ciência.

Em 2015, a Casa de Oswaldo Cruz, na Fundação Oswaldo Cruz, recebeu o acervo de José Reis, doado por sua família e composto por livros e documentos ${ }^{3}$. Entre os documentos, identificamos as memorias do evento de 1962, como descrito na Introdução deste artigo. Sob o cabeçalho "Primer Seminario Interamericano de Periodismo Científico”, o material inclui os conteúdos apresentados pelos diferentes palestrantes. Contém, ainda, um chamado

2 Para mais informações, ver https://radpc.org/ e https://www.facebook.com/redecomciencia/.

3 Para mais informações, sobre José Reis e o acervo, consultar o site http://josereis.coc.fiocruz.br/. 
informe do comitê, que sintetiza as discussões e traz recomendações de como consolidar o campo do jornalismo científico.

\section{Primeiro Seminário Interamericano de Jornalismo Científico}

\section{Os personagens}

O evento ocorreu ao longo de três dias, de 16 a 18 de outubro de 1962, organizado pela União Pan-americana da Secretaria Geral da Organização dos Estados Americanos e pelo Centro Técnico da Sociedade Interamericana de Imprensa.

Na programação, havia pessoas representando instituições cientificas e outras, representando a mídia. O quadro 1 mostra os personagens presentes nas apresentações:

Quadro 1 - Palestrantes no seminário, segundo programação preliminar ${ }^{4}$

\begin{tabular}{|c|c|c|c|c|c|}
\hline Palestrante & Instituição & País & Tema de fala & $\begin{array}{l}\text { Ciência } \\
\text { ou mídia? }\end{array}$ & $\begin{array}{l}\text { Conexão com } \\
\text { divulgação } \\
\text { científica }\end{array}$ \\
\hline $\begin{array}{l}\text { Ritchie } \\
\text { Calder }\end{array}$ & $\begin{array}{l}\text { Universidade } \\
\text { de Edimburgo }\end{array}$ & $\begin{array}{l}\text { Grã- } \\
\text { Bretanha }\end{array}$ & $\begin{array}{l}\text { Objetivo e prática } \\
\text { da popularização } \\
\text { da ciência }{ }^{5}\end{array}$ & Ciência & $\begin{array}{l}\text { Prêmio } \\
\text { Kalinga para a } \\
\text { Popularização da } \\
\text { Ciência, concedido } \\
\text { pela Unesco }\end{array}$ \\
\hline $\begin{array}{l}\text { Federico } \\
\text { Rutllant }^{7}\end{array}$ & $\begin{array}{l}\text { Observatório } \\
\text { Astronômico } \\
\text { Nacional } \\
\text { Chileno }\end{array}$ & Chile & (não indicado) & Ciência & (não identificado) \\
\hline $\begin{array}{l}\text { Raul Luis } \\
\text { Cardón }\end{array}$ & $\begin{array}{l}\text { Conselho } \\
\text { Nacional de } \\
\text { Pesquisas } \\
\text { Científicas e } \\
\text { Técnicas }\end{array}$ & Argentina & (não indicado) & Ciência & (não identificado) \\
\hline
\end{tabular}

4 Não foi identificada na documentação a programação definitiva. Portanto, não conseguimos saber se de fato as pessoas previstas compareceram, embora tenham enviado registro por escrito.

5 Foram mantidos os termos originais utilizados na documentação.

6 A palestra foi posteriormente publicada na revista Ciência e Cultura, v. 16, n. 3, em 1964.

7 Disponível em: http://www.memoriachilena.gob.cl/602/w3-printer-92385.html. Acesso em: 9 maio 2019. 


\begin{tabular}{|c|c|c|c|c|c|}
\hline Palestrante & Instituição & País & Tema de fala & $\begin{array}{l}\text { Ciência } \\
\text { ou mídia? }\end{array}$ & $\begin{array}{l}\text { Conexão com } \\
\text { divulgação } \\
\text { científica }\end{array}$ \\
\hline $\begin{array}{l}\text { Marcel } \\
\text { Roche }^{8}\end{array}$ & $\begin{array}{l}\text { Instituto } \\
\text { Venezuelano } \\
\text { de Pesquisas } \\
\text { Científicas }\end{array}$ & Venezuela & (não indicado) & Ciência & $\begin{array}{l}\text { Realizou ações } \\
\text { de divulgação } \\
\text { científica, entre } \\
\text { elas, programas } \\
\text { de TV e filmes. } \\
\text { Prêmio Kalinga da } \\
\text { UNESCO. }\end{array}$ \\
\hline $\begin{array}{l}\text { Crodowaldo } \\
\text { Pavan }^{9}\end{array}$ & $\begin{array}{l}\text { Universidade } \\
\text { de São Paulo }\end{array}$ & Brasil & $\begin{array}{l}\text { Desenvolvimento } \\
\text { da genética no } \\
\text { Brasil }\end{array}$ & Ciência & $\begin{array}{l}\text { Pavan participava } \\
\text { das "sextaferinas", } \\
\text { em que se } \\
\text { discutiam temas } \\
\text { culturais e } \\
\text { científicos, do } \\
\text { Instituto Biológico } \\
\text { nos anos } 1930 \text { e } \\
\text { inícios dos } 1940 ; \\
\text { na década de 1980, } \\
\text { foi fundamental } \\
\text { para a criação da } \\
\text { Estação Ciência, } \\
\text { um dos primeiros } \\
\text { museus interativos } \\
\text { brasileiros. }{ }^{10}\end{array}$ \\
\hline Enrique Pérez & $\begin{array}{l}\text { Jardim } \\
\text { Botânico de } \\
\text { Bogotá e El } \\
\text { Tiempo }\end{array}$ & Colômbia & $\begin{array}{l}\text { A divulgação } \\
\text { científica } \\
\text { jornalística }\end{array}$ & Ciência & $\begin{array}{l}\text { Editorialista } \\
\text { científico do jornal } \\
\text { El Tiempo, foi } \\
\text { diretor do Jardim } \\
\text { Botânico de Bogotá } \\
\text { e do Museu de } \\
\text { Ciências Naturais. }\end{array}$ \\
\hline
\end{tabular}

8 Com carreira científica, teve papel importante na ciência venezuelana, sendo secretário geral da Associação Venezuelana para o Avanço da Ciência (ASOVAC), fundador e diretor do Conselho Nacional Venezuelano de Pesquisa Científicas (CONICIT) e da revista acadêmica Interciencia. Disponível em: https://es.wikipedia.org/wiki/Marcel_Roche. Acesso em: 9 maio 2019.

9 Pavan foi um geneticista brasileiro que teve papel fundamental na construção da genética brasileira; foi presidente da Sociedade Brasileira para o Progresso da Ciência (1981-1986) e diretor-presidente da FAPESP (1981-1984). Para mais informações, ver Perondini (2010).

10 Para mais informações, ver Kreinz e Nunes (2010). 


\begin{tabular}{|c|c|c|c|c|c|}
\hline Palestrante & Instituição & País & Tema de fala & $\begin{array}{l}\text { Ciência } \\
\text { ou mídia? }\end{array}$ & $\begin{array}{l}\text { Conexão com } \\
\text { divulgação } \\
\text { científica }\end{array}$ \\
\hline $\begin{array}{l}\text { Jacobo } \\
\text { Brailovsky }^{11}\end{array}$ & La Nación & Argentina & $\begin{array}{l}\text { Missão do } \\
\text { jornalismo na } \\
\text { divulgação } \\
\text { científica }\end{array}$ & $\begin{array}{l}\text { Mídia e } \\
\text { Ciência }\end{array}$ & $\begin{array}{l}\text { Importante } \\
\text { personagem } \\
\text { no jornalismo } \\
\text { científico argentino } \\
\text { e ibero-americano. }\end{array}$ \\
\hline José Reis ${ }^{12}$ & $\begin{array}{l}\text { Jornal da } \\
\text { Manha } \tilde{a}^{13}\end{array}$ & Brasil & $\begin{array}{l}\text { Objetivos e } \\
\text { políticas de } \\
\text { cobrir temas de } \\
\text { ciência }\end{array}$ & $\begin{array}{l}\text { Mídia e } \\
\text { Ciência }\end{array}$ & $\begin{array}{l}\text { Importante } \\
\text { personagem } \\
\text { no jornalismo } \\
\text { científico brasileiro } \\
\text { e ibero-americano. } \\
\text { Prêmio Kalinga da } \\
\text { UNESCO. }\end{array}$ \\
\hline $\begin{array}{l}\text { Hillier } \\
\text { Krieghbaum }^{14}\end{array}$ & $\begin{array}{l}\text { Universidade } \\
\text { de Nova York }\end{array}$ & $\begin{array}{l}\text { Estados } \\
\text { Unidos }\end{array}$ & $\begin{array}{l}\text { Capacitação de } \\
\text { escritores de } \\
\text { ciência }\end{array}$ & Mídia & $\begin{array}{l}\text { Vinculado ao } \\
\text { departamento de } \\
\text { jornalismo }\end{array}$ \\
\hline $\begin{array}{l}\text { Alberto } \\
\text { Hurtado }\end{array}$ & $\begin{array}{l}\text { Universidade } \\
\text { Peruana de } \\
\text { Ciências } \\
\text { Médicas e } \\
\text { Biológicas } \\
\end{array}$ & Peru & $\begin{array}{l}\text { Pesquisas } \\
\text { médicas nas } \\
\text { alturas }\end{array}$ & Ciência & (não identificado) \\
\hline John Foster & $\begin{array}{l}\text { Universidade } \\
\text { de Columbia }\end{array}$ & $\begin{array}{l}\text { Estados } \\
\text { Unidos }\end{array}$ & $\begin{array}{l}\text { Problemas e } \\
\text { oportunidades } \\
\text { em cobrir temas } \\
\text { de ciência }\end{array}$ & Mídia & $\begin{array}{l}\text { Vinculado ao } \\
\text { departamento de } \\
\text { jornalismo }\end{array}$ \\
\hline $\begin{array}{l}\text { Hugo de } \\
\text { Almeida } \\
\text { Leme }^{15}\end{array}$ & $\begin{array}{l}\text { Escola } \\
\text { Superior de } \\
\text { Agricultura } \\
\text { Luiz de } \\
\text { Queiroz }\end{array}$ & Brasil & $\begin{array}{l}\text { Agronomia no } \\
\text { Brasil }\end{array}$ & Ciência & (não identificado) \\
\hline
\end{tabular}

11 Importante personagem do jornalismo científico argentino e ibero-americano. Médico de formação, foi um dos fundadores e presidente da Associação Argentina de Jornalismo Científico, um dos fundadores e vice-presidente da Associação Ibero-americana de Jornalismo Científico e foi colaborador permanente do jornal La Nación. Disponível em: https://www.fundacionkonex.org/b1161jacobo-brailovsky. Acesso em: 9 maio 2019.

12 Massarani, Burlamaqui e Passos (2018).

13 Segunda a documentação encontrada em seu acervo, José Reis estaria vinculado à Folha da Manhã. No entanto, segundo o Grupo Folha o jornal já tinha deixado de existir, visto que em 1 de janeiro de 1960 os três títulos da empresa ("Folha da Manhã”, "Folha da Tarde" e "Folha da Noite") se fundiram e surgiu o jornal Folha de S.Paulo. Disponível em: https://www1.folha.uol.com.br/institucional/ historia_da_folha.shtml?fill=4. Acesso em: 10 maio 2019.

14 Disponível em: https://www.nytimes.com/1993/03/18/obituaries/hillier-krieghbaum-nyu-professor-90.html. Acesso em: 9 maio 2019.

15 Agrônomo e político brasileiro. Disponível em: http://www.fgv.br/cpdoc/acervo/dicionarios/verbete-biografico/hugo-de-almeidaleme. Acesso em: 9 maio 2019. 


\begin{tabular}{|c|c|c|c|c|c|}
\hline Palestrante & Instituição & País & Tema de fala & $\begin{array}{l}\text { Ciência } \\
\text { ou mídia? }\end{array}$ & $\begin{array}{l}\text { Conexão com } \\
\text { divulgação } \\
\text { científica }\end{array}$ \\
\hline $\begin{array}{l}\text { Román } \\
\text { Arana- } \\
\text { Iñiguez }^{16}\end{array}$ & $\begin{array}{l}\text { Hospital de } \\
\text { Clínicas }\end{array}$ & Uruguai & (não indicado) & Ciência & (não identificado) \\
\hline $\begin{array}{l}\text { Alberto } \\
\text { Giesecke }\end{array}$ & $\begin{array}{l}\text { Instituto } \\
\text { Geofísico do } \\
\text { Peru }\end{array}$ & Peru & (não indicado) & Ciência & (não identificado) \\
\hline Earl Ubell & $\begin{array}{l}\text { Herald } \\
\text { Tribune }\end{array}$ & $\begin{array}{l}\text { Estados } \\
\text { Unidos }\end{array}$ & $\begin{array}{l}\text { Como jornais dos } \\
\text { Estados Unidos } \\
\text { cobrem temas de } \\
\text { ciência }\end{array}$ & Mídia & $\begin{array}{l}\text { Editor da seção de } \\
\text { ciência }\end{array}$ \\
\hline $\begin{array}{l}\text { Napoleón } \\
\text { Vieira } \\
\text { Altamira }\end{array}$ & $\begin{array}{l}\text { El Diario de } \\
\text { Hoy }\end{array}$ & $\begin{array}{l}\text { El } \\
\text { Salvador }\end{array}$ & (não indicado) & Ciência & (não identificado) \\
\hline
\end{tabular}

Trata-se de um universo totalmente masculino, com todos os 16 palestrantes homens, provenientes de oito países: Argentina, Brasil, Chile, Colômbia, Estados Unidos, GrãBretanha, Peru, Venezuela. O peso dado a representantes da ciência foi maior que da mídia, sendo 11 pessoas ligadas a instituições científicas. Cinco pessoas vinham de jornais - duas delas com formação científica - e duas de Departamento de Jornalismo em universidades.

Segundo a lista de participantes, o encontro reuniu cerca de 30 pessoas, incluindo outros representantes de mídia (La Prensa, Peru, El telégrafo, Equador, La Nación, Costa Rica, La Prensa, Argentina, El Norte e Novedades, México, Los Principios, Argentina), da Fundação Ford, da Fundação Rockefeller e do Banco Mundial para Reconstrução e Desenvolvimento.

Entre os palestrantes, destacam-se nomes de personagens que tiveram um papel importante no jornalismo científico e/ou na divulgação científica de seus países, como o próprio brasileiro José Reis, o argentino Jacobo Brailovsky e o venezuelano Marcel Roche. O médido e jornalista Brailovsky começou a atuar no jornal La Nación em 1924, no qual manteve uma coluna semanal; foi fundador e primeiro presidente da Associação Argentina de Jornalismo Científico. Roche era pesquisador, na ocasião atuando no Instituto Venezuelano de Pesquisas Científicas. Teve um papel importante na construção da ciência venezuelana, atuando na Associação Venezuelana para o Avance da Ciência (ASOVAC) e do Conselho Nacional Venezuelano de Pesquisas Científicas e Tecnológicas (CONICIT); por suas iniciativas em divulgação cientifica ganhou o Prêmio Kalinga da UNESCO em 1987 o mais importante prêmio internacional em popularização da ciência.

16 Médico e pesquisador. Disponível em: http:/historiasuniversitarias.edu.uy/biografia/arana-iniguez-roman/. Acesso em: 9 maio 2019. 
Outros personagens claramente atuavam no campo na ocasião, como o norteamericano Earl Ubell, que em 2007 seria considerado pelo jornal New York Times como “aquele que iluminou o público com temas de ciência”, era físico de formação e atuou como jornalista de ciência e editor, iniciando sua carreira nos anos 1950 no The New York Herald Tribune ${ }^{17}$.

Já outros parecem ser cientistas importantes em seus países, mas com uma inserção menos clara na divulgação científica, como Hugo de Almeida Leme, agrônomo e político, que foi ministro da agricultura em nosso país, e optou por falar da agronomia no país.

Na documentação analisada, nem sempre é claro o tema das apresentações dos palestrantes. Mas, pelas informações, identificamos que pelo menos oito dos 16 palestrantes abordaram questões da divulgação científica. Em pelo menos cinco, o tema se restringiu a questões científicas, como o brasileiro Crodowaldo Pavan, que relatou a construção da genética no Brasil, e o peruano Alberto Hurtado, que falou de pesquisas médicas nas alturas. Já Federico Rutllant e Alberto Giesecke fizeram uma apresentação institucional, respectivamente, realizaram uma descrição do Observatório Astronômico Nacional Chileno e do Instituto Geofísico do Peru. Hugo de Almeida Leme falou sobre a agronomia brasileira.

Entre os palestrantes de fora da região latino-americana, observam-se esforços de compartilhar a realidade de outros países. Foi o caso de Earl Ubell - na ocasião era editor de ciência do Herald Tribune há 10 anos -, que trouxe para o evento o contexto dos Estados Unidos, em que a cobertura de ciência tinha crescido por uma demanda do próprio público. Ele afirmou: “O interesse gerado pelas bombas atômicas, pela vacina contra a poliomielite de Salk, os foguetes, a astronomia moderna, penetraram o santuário do editor”18. Segundo Ubell, havia, na ocasião, 1.700 jornais diários em seu país e entre 100 e 200 escritores de ciência, o que seria insuficiente.

\section{Tópicos discutidos}

\section{Porque fazer divulgação científica}

Sendo o universo de participantes com maior peso de representantes da ciência, a ênfase se deu na necessidade de dar visibilidade à ciência e criar condições de trabalho para os cientistas, como pode ser visto no discurso inaugural, proferido por John Reitemeyer, vicepresidente da Sociedade Interamericana de Imprensa e gerente do Hartford Courant, jornal do estado de Connecticut, nos Estados Unidos. Ele destacou que os brilhantes e dedicados 'homens' que atuam na ciência não são conhecidos em seus países, o que leva a uma falta de condições de trabalho e consequente evasão de cérebros. Em uma discussão bastante contemporânea, citou o caso da Argentina e os cortes em 10\% em salários de cientistas de

17 Earl Ubell, Who Enlightened Public on Science, Dies at 80, The New Yourk Times, 31 de maio de 2007. Disponível em: https:// www.nytimes.com/2007/05/31/nyregion/31ubell.html. Acesso: 29 dez. 2020.

18 "How United States newspapers publish science", Earl Ubell, p. 2. 
alto nível. Reitemeyer defendeu que a ciência e a mídia unissem esforços e entrassem em uma cruzada para aumentar a compreensão pública da ciência e, consequentemente, existir um maior apoio à ciência.

Na mesma linha, o argentino Raul Luis Gardon enfatizou a necessidade de a ciência ter apoio do estado, afirmando ser "imprescindível que os governantes sejam persuadidos da conveniência e necessidade de a de ajudar a ciência e de aplicar seus resultados para a solução de muitos problemas locais”19.

Gardon mencionou ainda ser:

Igualmente importante criar um estado de opinião favorável ao trabalho científico; fazer compreender o valor da ciência (cultural, social, utilitário); a hierarquia do pesquisador e a transcendência de sua obra. Isto não apenas facilitará a obtenção de apoio estatal e de outros setores (como o empresarial), como também favorecerá a multiplicação de vocações científicas e maior dedicação à pesquisa ${ }^{20}$.

Já José Reis defendeu que a popularização da ciência por meio de todos os meios disponíveis é um elemento importante na formação da atitude do cidadão moderno em relação à ciência e aos problemas que ela suscita:

Essa importância, embora seja grande nas nações desenvolvidas, onde existe um sistema educativo adequado, é ainda mais importante nas nações subdesenvolvidas, onde o sistema educativo não consegue dar uma boa formação científica. Nesses países, o popularizador da ciência assume a alta responsabilidade de criar no povo uma atitude crítica que compense as deficiências do sistema educativo ${ }^{21}$.

\section{O que e como fazer divulgação científica}

José Reis defendeu que a divulgação científica deve:

1) Destacar o valor da ciência em geral e evitar acentuar a diferença entre ciência pura e aplicada. 2) Tender ao ensino de princípios fundamentais e de atitudes científicas, usando para este fim as motivações adequadas que oferecem os avanços da ciência e da tecnologia, mas evitando dar a ideia de que só a novidade e o espetacular merece o nome de ciência. 3) Focar a atenção

19 “Necesidad y dificultades del desarrollo científico-técnico en América Latina. Contribución del periodismo a este desarrollo”, Raúl Luis Cardón, p. 1.

20 “Necesidad y dificultades del desarrollo científico-técnico en América Latina. Contribución del periodismo a este desarrollo”, Raúl Luis Cardón, p. 1.

21 “Fines y políticas del periodismo científico”, José Reis, p. 1. 
no desenvolvimento das ideias e atividades científicas no país e não apenas aos eventos que ocorrem no estrangeiro. 4) Dar atenção a aspectos aos aspectos históricos da ciência e tecnologia. 5) Considerar as relações entre ciência e sociedade, destacando a utilidade de uma cooperação estreita entre as ciências e as disciplinas humanistas. 6) Dar ao público uma ideia fiel do cientista como um dos fatores do progresso social mas não o único nem o principal, sobretudo, o público não deve ser induzido à ideia errônea de que o cientista pertence a uma casta superior, privilegiada ${ }^{22}$.

Earl Ubell entrou em questões práticas do cotidiano do jornalista, como a questão das fontes. A seu ver, cobrir eventos nacionais, "permite entrar em contato com vários cientistas, seu trabalho e sua forma de pensar. É uma fonte imensa de ideias ara matérias futuras e possibilidade de saber de matérias que irão vir”23.

Com uma abordagem contemporânea, Ubell citou os journals especializados referindo-se especificamente aos periódicos científicos mais usados atualmente entre jornalistas científicos, como Science, Nature, Lancet, British Medical Journal e New England Journal of Medicine, além de Scientific America. Mas comentou a dificuldade de selecionar os journals mais relevantes, especialmente para a realidade latino-americana.

Destacou, ainda, a importância de usar imagens e desenhos para atrair a atenção dos leitores.

\section{Quem deve fazer divulgação científica: o cientista ou o jornalista?}

Também presente no evento foi a discussão sobre quem deve divulgar a ciência: o cientista ou o jornalista. O argentino Jacobo Brailowsky defendeu que ambos podem divulgar, mas que, para uma boa divulgação, é necessária uma expertise jornalística que poucos cientistas possuem.

Já José Reis defendeu que a popularização científica “é um dever de todos os cientistas, cujo trabalho depende em grande medida a compreensão da ciência por parte do público geral”. ${ }^{24}$ Para ele, o cientista deve atender a este dever direta ou indiretamente, no último caso "em uma estreita colaboração com os jornalistas leigos”25.

Mais recorrente nas falas dos palestrantes foi a defesa de que deve existir uma parceria entre jornalistas e cientistas. Foi o caso do venezuelano Marcel Roche, que focou parte de sua fala em compartilhar a experiência de como "em um país praticamente sem tradição científica, jornalistas e cientistas têm conseguido cooperar, apoiando a ciência e ajudando-a a crescer”. Expressando uma visão utilitária do jornalismo científico, Roche afirma que

22 “Fines y políticas del periodismo científico”, José Reis, p. 2.

23 "How United States newspapers publish science”, Earl Ubell, p. 2.

24 “Fines y políticas del periodismo científico”, José Reis, p. 1.

25 “Fines y políticas del periodismo científico”, José Reis, p. 1. 
a mídia tem demonstrado um grande interesse em "servir” o Instituto Venezuelano de Pesquisas Científicas, tornando pública sua pesquisa e seu progresso ${ }^{26}$.

Essas ideias foram replicadas no informe do comitê:

É necessário que exista entre o cientista e o jornalista um melhor entendimento mútuo do trabalho que realizam para a sociedade. O jornalista necessita melhorar sua formação profissional, e o cientista adotar uma atitude de compreensão que contribua para facilitar o trabalho de informação, divulgação e interpretação do progresso das ciências básicas e aplicadas ${ }^{27}$.

\section{Capacitação}

A capacitação de jornalistas para cobrir temas de ciência foi recorrente em várias falas, entre elas a de Reitemeyer, que defendeu que deve haver capacitação, com seminários do tipo do que ocorreu em 1962, para quem trabalha na rádio e na TV, e de Hillier Krieghbaum, que apresentou um plano mais detalhado de estratégias diferenciadas.

Segundo o informe do comitê, destacou-se a importância de fortalecer a formação de jornalistas atuantes e alunos, incluindo (1) preparação de materiais didáticos e (2) cursos e seminários destinados a estabelecer contatos com cientistas ${ }^{28}$. Recomendou-se, também, no informe, a criação de disciplinas em cursos universitários em jornalismo de jornalismo científico, bem como a publicação de manuais de divulgação cientifica e de uma lista dos divulgadores e jornalistas científicos. Também foi proposto que agências de fomento dedicasse bolsas de estudos em jornalismo científico.

A criação de uma associação de jornalismo científico ibero-americana também foi sugerida, o que ocorreu em 1969.

\section{Considerações finais}

Neste texto, analisamos os personagens e os conteúdos presentes no evento de jornalismo científico em 1962. Um primeiro aspecto que surge é a questão dos personagens em jogo: enquanto na ocasião se tratava de um universo unicamente masculino e havia preponderância de cientistas, atualmente mais mulheres ocupam o cenário do jornalismo científico e da divulgação científica em geral, inclusive superando em número. Desde então, também houve uma maior diversificação de atores sociais, inclusive com a chegada e crescimentos dos museus interativos de ciência (MASSARANI et al., 2012, MASSARANI et al., 2015, MASSARANI et al., 2017, PATIÑO et al., 2019).

26 “Science and newspaper, a personal experience", Marcel Roche, p. 1.

27 “Informe del comité”, n.1, p. 1.

28 Informe del comité, n.1, p. 2. 
Justamente por ter sido um evento com maior presença de cientistas, a discussão do porquê fazer divulgação científica teve maior peso em seu caráter utilitário do jornalismo científico para apoiar a ciência. Mas a discussão foi além disso, especialmente na fala de José Reis, que defendeu uma visão bastante contemporânea, em que se atribui à divulgação científica um papel na formação de cidadania científica ${ }^{29}$.

Outro tema bastante contemporâneo foi a ênfase na capacitação. Se implementado, o plano proposto no documento de síntese do documento poderia ter tido um impacto importante nas novas gerações. Mesmo sem tal proposta ser implementada, de fato vimos que o movimento em prol do jornalismo científico cresceu, o que levou à criação de associações nacionais e de editorias de ciência em vários jornais da região. Infelizmente, muitas dessas associações, inclusive a ibero-americana e a brasileira, perderam sua força, sendo, em alguns poucos casos, substituídas por redes; muitos jornais perderam equipes e a própria editoria. Em outras palavras, ao longo dos mais de 50 anos depois desse evento precursor, vimos o crescimento do campo e sua posterior retração - embora a área da divulgação científica em geral tenha crescido muito na região. É a hora de fazermos um novo evento - e um novo movimento - inspirador.

\section{Referências}

CALVO HERNANDO, M. Arte y ciencia de divulgar el conocimiento. Quito: Ciespal, 2006. Disponível em: https://biblio.flacsoandes.edu.ec/catalog/resGet.php?resId=43116. Acesso em: 10 maio 2019.

CALVO HERNANDO, M. Ciencia y periodismo científico en Iberoamérica. Diálogos, La Insignia, Espanha, março de 2005. Disponível em: http://www.lainsignia.org/2005/marzo/dial_002.htm. Acesso em: 10 maio 2019.

KREINZ, G.; NUNES, O. Pavan: o extravagante divulgador científico. Cienc. Cult., São Paulo, v. 62, n. spe2, p. 14-15, 2010. Disponível em: http://cienciaecultura.bvs.br/scielo.php?script=sci_arttext\&pid=S000967252010000600005\&lng=en\&nrm=iso. Acesso em: 29 dez. 2020.

MASSARANI, L.; DIAS, E. (Org.). José Reis: reflexões sobre a divulgação científica. Rio de Janeiro: Casa de Oswaldo Cruz, 2018.

MASSARANI, L. Science communication in Latin America, In: PRIEST, S. (Ed.). Encyclopedia of science and technology communication. Thousand Oaks, CA: SAGE Publications, 2010, p. 443-445.

MASSARANI, L.; AMORIM, L.; BAUER, M., MONTES DE OCA, A. Periodismo científico: reflexiones sobre la práctica en América Latina. Chasqui, n. 120, 2012, p.73-77.

MASSARANI, L.; BURLAMAQUI, M.; PASSOS, J. José Reis, caixeiro-viajante da ciência. Rio de Janeiro: Casa de Oswaldo Cruz, 2018.

MASSARANI, L.; LEON-CASTELLA, A.; AGUIRRE, C.; REYNOSO, E.; LINDERGAARD, L.; FERNANDEZ, E. (Org.). Guia de Centros e Museus de Ciência da América Latina e do Caribe. Rio de Janeiro: RedPOP-UNESCO e Museu da Vida, 2015. 566p.

29 Mais textos de Reis sobre a área podem ser lidos em Massarani e Dias (2018). 
PATIÑO, M. L.; PADILlA, J.; MASSARANI, L. Public engagement in science: Mapping out and understanding the practice of science communication in Latin America. Anais da Academia Brasileira de Ciências, v. 91, p. 1-16, 2019.

PERONDINI, A. L. Crodowaldo Pavan e a genética no Brasil. Ciência e Cultura, v. 62, n. spe2, p. 5-8, 2010. Disponível em: http://cienciaecultura.bvs.br/scielo.php?script=sci_arttext\&pid=S000967252010000600002\&lng=en\&nrm=iso. Acesso em: 9 maio 2019.

\section{Luisa Massarani}

Coordenadora do Instituto Nacional de Comunicação Pública da Ciência e Tecnologia, sediado na Casa de Oswaldo Cruz, Fundação Oswaldo Cruz (Fiocruz). É docente do Mestrado Acadêmico em Divulgação da Ciência, Tecnologia e Saúde da Casa de Oswaldo Cruz, da Pós-Graduação em Ensino em Biociências e Saúde no Instituto Oswaldo Cruz/Fiocruz e no Instituto de Bioquímica Médica da Universidade Federal do Rio de Janeiro. Bolsista Produtividade do CNPq 1C. Cientista do Nosso Estado da Faperj. E-mail: luisa.massarani@fiocruz.br.

Recebido em: 13.05.2019

Aprovado em: 30.12.2020

Este artigo é publicado em acesso aberto (Open Access) sob a licença Creative Commons Attribution Non-Commercial (CC-BY-NC), que permite uso, distribuição e reprodução em qualquer meio, sem restrições, desde que sem fins comerciais e que o trabalho original seja corretamente citado. 